\title{
EFEITO DO NÍVEL ENERGÉTICO E DA SUPLEMENTAÇÃO COM CLORETOS DE POTÁSSIO E DE AMÔNIA NA DIETA SOBRE AS RESPOSTAS FISIOLÓGICAS E O DESEMPENHO DE FRANGOS DE CORTE NO VERÃO ${ }^{1}$
}

\author{
Effect of the energy level and supplementation with potassium and ammonium chlorides in the \\ diet on the physiological parameters and the performance of broiler in the summer
}

\author{
Bonifácio Benício de Souza ${ }^{2}$, Antônio Gilberto Bertechini ${ }^{3}$, Antônio Soares Teixeira ${ }^{3}$, \\ José Augusto de Freitas Lima ${ }^{3}$, Ademir José Conte ${ }^{3}$
}

\begin{abstract}
RESUMO
Realizou-se este estudo com o objetivo de verificar o efeito do nível energético da ração e da suplementação com cloretos de potássio e de amônia na dieta de frangos de corte no verão. Foram utilizados 240 frangos machos, Hubbard, com peso médio inicial de 1204 g, distribuídos num delineamento inteiramente casualizado, em esquema fatorial 2 x 3 x 2, 2 níveis de KCl $(0,0 \%$ e 1,2\%) x 3 níveis de $\mathrm{NH} 4 \mathrm{Cl}(0,0 \%, 0,2 \%$ e 0,4\%) x 2 níveis de energia (3000 e $3200 \mathrm{Kcal} \mathrm{EM/kg} \mathrm{de} \mathrm{ração),} \mathrm{com} 4$ repetições de 5 aves por repetição. $\mathrm{O}$ índice de temperatura do globo negro e umidade (ITGU), observado às 9 horas e 15 horas foi de 76 e 83, respectivamente. Houve interação $(\mathrm{P}<0,01)$ do $\mathrm{KCl}$ com $\mathrm{NH} 4 \mathrm{Cl}$ para a temperatura superficial. O nível energético da ração afetou $(\mathrm{P}<0,01)$ a temperatura superficial no turno da tarde. Para a temperatura retal, freqüência respiratória, $\mathrm{pH}$ do sangue e o desempenho não se verificou efeito $(\mathrm{P}>0,05)$ dos fatores estudados. A ingestão de água aumentou $(\mathrm{P}<0,05)$ com a adição de KCl. Para a conversão alimentar houve melhora $(\mathrm{P}<0,05)$ com a elevação do nível energético e piora $(\mathrm{P}<0,05)$ com o nível mais elevado de cloreto de amônia. Houve interação $(\mathrm{P}<0,05)$ entre o $\mathrm{KCl}$ e o nível energético da ração para o consumo de ração. Concluiu-se que, nas condições deste experimento, os fatores estudados não afetam a temperatura retal, freqüência respiratória, pH sanguíneo nem o desempenho de frangos de corte. Porém, a conversão alimentar melhora com a elevação do nível energético da ração e piora com a adição de cloreto de amônia à dieta em nível alto.
\end{abstract}

Termos para indexação: energia metabolizável, estresse calórico, cloreto de amônia, frango de corte, desempenho.

\begin{abstract}
Two hundred and forty male chickens with weight means initial of $1204 \mathrm{~g}$, were utilized and allocated according to a completely randomized design , with treatments arranged in a factorial scheme 2 × 3 x 2, 22 levels of $\mathrm{KCl}(0,0 \%$ and $1,2 \%)$ x 3 levels of $\mathrm{NH} 4 \mathrm{Cl}(0,0 \%, 0,2 \%$ and 0,4\%) x 2 levels of Metabolizable Energy (3000 and $3200 \mathrm{Kcal} \mathrm{ME} / \mathrm{kg}$ of diets), with four replications with five broilers in each. The index of temperature of the black globe and humidity (ITGU) was observed at 9:00 and 15:00 hours which was of 76 and 83, respectively. There was a significant interaction $(\mathrm{P}<0,01)$ of $\mathrm{KCl}$ with $\mathrm{NH} 4 \mathrm{Cl}$ for the surface temperature. The energetic level of diet $(\mathrm{P}<0.01)$ was affected by the surface temperature in the afternoon. The variables rectal temperature, respiratory frequency, $\mathrm{pH}$ of the blood and the performance were not significant effect $(\mathrm{P}>0,05)$ by the treatments studied. The water intake increased $(\mathrm{P}<0,05)$ with the addition of $\mathrm{KCl}$ in the diet. The feed conversion shown to be better $(\mathrm{P}<0,05)$ with the increasing the energy level in the diets and it was worse $(\mathrm{P}<0,05)$ at the highest level of chloride of ammonia added in the diets. There was significant interaction $(\mathrm{P}<0,05)$ between $\mathrm{KCl}$ and the energy level of the diets for feed intake. It was conclude that, studied factors do not affect any of the physiologics parameters studied as well as the broiler performance except for feed conversion that shown better with the by the increasing energy level of the diet and shown to be worse by the addition high level of chloride of ammonia in the diet.
\end{abstract}

Index terms: metabolizabel energy, heat stress, ammonium chloride, broiler chicken, performance.

(Recebido para publicação em 24 de setembro de 2003 e aprovado em 24 de novembro de 2004)

\section{INTRODUÇÃO}

Em ambientes quentes os frangos respondem com redução no consumo alimentar, para minimizar a produção de calor (CAMPOS, 1999). De acordo com Cooper e Washburn (1998), o consumo de ração, ganho de peso e conversão alimentar de frangos de corte estão correlacionados com a temperatura corporal. As respostas termorregulatórias dependem do gradiente térmico entre a temperatura superficial dos frangos e a do ambiente. De acordo com Campos (1995), a temperatura superficial é a média das temperaturas obtidas no dorso,

1. Parte da Tese de Doutorado do primeiro autor (Pesquisa financiada pela FAPEMIG).

2. Professor do Departamento de Medicina Veterinária do CSTR/UFPB - Campus VII, Patos, PB - 58700-000 - bonif@cstr.ufcg.edu.br

3. Professores do Departamento de Zootecnia/Universidade Federal de Lavras/UFLA - Caixa Postal 3037 - 37.200-000 - Lavras, MG.

4. Aluno do Doutorado em Zootecnia/UFLA. 
na base da crista, cabeça, asa direita e perna esquerda (região do tarso e do metatarso). Richards (1971), submetendo frangos de corte a diferentes temperaturas ambiente (20, 30 e $\left.40^{\circ} \mathrm{C}\right)$, registrou temperatura superficial média de $30,8,38,7$ e $41,1^{\circ} \mathrm{C}$, nas respectivas temperaturas e observou variações de 11 a $20^{\circ} \mathrm{C}$ nas áreas desprovidas de penas e de 2 a $5^{\circ} \mathrm{C}$ em áreas cobertas de penas, quando a temperatura variou de 20 para $40^{\circ} \mathrm{C}$. Nutricionalmente, tem se buscado melhorar o desempenho dos frangos de corte, no verão, elevando o nível de energia da ração bem como a com a adição de cloretos de potássio e de amônia à dieta. Deyhim e Teeter (1991), ao suplementarem a água de frangos de corte com $0,5 \%$ de $\mathrm{KCl}$, sob estresse calórico cíclico (24 - 35oC), verificaram efeito do $\mathrm{KCl}$ sobre o consumo de água e equilíbrio ácido-básico. Teeter e Smith (1986), quando suplementaram a água com $0,15 \%$ de $\mathrm{KCl}$, verificaram que as aves não tiveram o $\mathrm{pH}$ sangüíneo alterado, mas tiveram melhora no desempenho.

Souza et al. (2002a) verificaram efeito significativo de $\mathrm{KCl}$ no $\mathrm{pH}$ sangüíneo de frangos de corte criados durante o verão. E Souza et al. (2002b), verificaram que o nível energético da ração melhorou a conversão alimentar durante o estresse por calor.

Branton et al. (1986), suplementando a água de bebida com $\mathrm{NH} 4 \mathrm{Cl}$ nos níveis de 0,63 e 3,1\% no período de 42 a 52 dias de criação, verificaram que o nível de $0,63 \%$ não afetou a ingestão de água, porém, o nível de 3,1\% de $\mathrm{NH} 4 \mathrm{Cl}$ afetou significativamente este parâmetro (redução de 79\%) e elevou o índice de mortalidade (de 16 para 49\%). Frangos de corte, sob temperatura ambiente de 32oC, tratados com ração suplementada com níveis de 0,3; 1,0 e 3,0\% de $\mathrm{NH} 4 \mathrm{Cl}$ no período de 28 a 49 dias, apresentaram o melhor desempenho com o nível de 1,0\% (TEETER et al., 1985).

O consumo de ração das aves está inversamente relacionado à temperatura ambiente (SAKOMURA et al., 1993). Sob temperaturas elevadas os frangos aumentam a exigência de energia para dissipar o excesso de calor corporal, o que prejudica a conversão alimentar (CERNIGLIA et al., 1983).

Objetivou-se com este trabalho, estudar os efeitos da suplementação de cloretos de potássio e de amônia na dieta e do nível energético da ração sobre a temperatura corporal, temperatura superficial, freqüência respiratória, pH sangüíneo, consumo de água e o desempenho de frangos de corte sob estresse por calor.

\section{MATERIAL E MÉTODOS}

O experimento foi realizado no setor de Avicultura do Departamento de Zootecnia da Universidade Federal de Lavras. Foram utilizados 240 frangos de corte, machos, Hubbard, durante o período de 28 a 49 dias de criação, no verão, distribuídos segundo um delineamento inteiramente casualizado, no esquema fatorial $2 \mathrm{x}$ 3 x 2, sendo 2 níveis de $\mathrm{KCl}(0,0$ e 1,2\%); 3 níveis de $\mathrm{NH} 4 \mathrm{Cl}(0,0,0,2$ e $0,4 \%)$ e 2 níveis de energia (3.000 e 3.200 Kcal de Energia Metabolizável por kg de ração), com 4 repetições e 5 aves por repetição. Utilizou-se um galpão de alvenaria, com dimensões de 6 x 8 metros, com paredes laterais de $1,5 \mathrm{~m}$ de altura e o restante de telas, com cortinas e cobertura com telhas de cimentoamianto, equipado com quatro conjuntos de baterias metálicas, de quatro andares e três gaiolas por andar, medindo 94 x 94 x $32 \mathrm{~cm}$ de frente, fundo e altura, respectivamente. Durante o período experimental foram registrados os dados climáticos local. Analisaram-se os parâmetros: temperatura retal (TR), temperatura superficial (TS), freqüência respiratória (FR), $\mathrm{pH}$ sangüíneo $(\mathrm{pH})$, ingestão de água (IA), consumo de ração (CR), ganho de peso (GP) e conversão alimentar (CA). As mensurações da TR e FR foram realizadas duas vezes por semana, às 9 horas e 15 horas, dos 28 aos 49 dias de idade. Para a determinação da temperatura retal (TR) utilizou-se um termômetro clínico veterinário (Digital KD-108 A), introduzindo-o a uma profundidade de $4 \mathrm{~cm}$ no reto das aves, por um período de 1 minuto. A TS foi obtida por meio da média das temperaturas da pele de seis pontos determinados do corpo da ave: dorso, entre as escápulas, na base da crista, na cabeça, nas faces interna e externa da asa direita e na perna esquerda (região do tarso e do metatarso), utilizando um termômetro infravermelho (ST3-RAYTEK). A FR foi obtida por meio da auscultação indireta, com o auxílio de um estetoscópio flexível, e expressa em movimentos por minuto (mov/min). Foram sorteados quatro frangos de cada tratamento para coleta de sangue, com o objetivo de determinar o $\mathrm{pH}$ sangüíneo.Foram obtidas com seringas heparinizadas amostras de $3 \mathrm{ml}$ de sangue, da veia da asa, e imediatamente após a coleta foi realizada a análise por meio de um "Corning Blood pH/Gas Analyser".

A ingestão de água (IA) foi determinada durante um período de quatro dias, quando as aves atingiram a idade de 42 dias. Determinou-se o consumo médio pelo fornecimento de água, em bebedouro tipo calha, medida por meio de um becker duas vezes ao dia, e a mensuração da sobra foi feita na manhã do dia seguinte. 
O fornecimento de ração e de água durante todo o período de criação, foi à vontade. As dietas experimentais foram preparadas à base de milho e farelo de soja, suplementadas com minerais e vitaminas, balanceadas de acordo com as recomendações de Rostagno et al. (1994), conforme (Tabela 1).

O consumo de ração (CR) foi determinado por diferença entre a quantidade de ração oferecida e a sobra, diariamente. Os frangos foram pesados a cada sete dias, e o ganho de peso (GP) e a conversão alimentar (CA) foram calculados para o período de 28 a 49 dias de idade. Os dados obtidos foram analisados estatisticamente pelo programa estatístico Statistical Analyses System (SAS INSTITUTE, 1996).

TABELA 1 - Composição das dietas experimentais.

\begin{tabular}{lcc}
\hline \multicolumn{1}{c}{ Ingredientes } & Dieta 1 (Nível energético baixo) & Dieta 2 (Nível energético alto) \\
\hline & $(\%)$ & $(\%)$ \\
Milho moído & 62,68 & 57,66 \\
Farelo de Soja & 29,95 & 30,89 \\
Fosfato Bicálcico & 1,61 & 1,85 \\
Calcário & 0,99 & 0,83 \\
Óleo de soja & 1,92 & 5,92 \\
Suplemento vitamínico & 0,20 & 0,20 \\
Suplemento mineral ${ }^{1}$ & 0,10 & 0,10 \\
DL- metionina - 99\% & 0,15 & 0,15 \\
Sal comum & 0,40 & 0,40 \\
Porção variável* & 2,00 & 2,00 \\
TOTAL & $\mathbf{1 0 0 , 0 0}$ & $\mathbf{1 0 0 , 0 0}$ \\
\hline Composição nutritiva: & & 3.200 \\
\hline EM (kcal/kg) & 3.000 & 19,00 \\
Proteína Bruta(\%) & 19,00 & 0,36 \\
Metionina(\%) & 0,39 & 0,71 \\
Metionina + cistina (\%) & 0,71 & 1,05 \\
Lisina(\%) & 1,05 & 0,63 \\
Treonina(\%) & 0,63 & 0,90 \\
Cálcio(\%) & 0,90 & 0,44 \\
Fósforo disponível(\%) & 0,44 & \\
\hline
\end{tabular}

1. Enriquecimento por kg de ração: Vit. A, 9600 UI; $D_{3}, 1800$ UI; $K_{3}, 2,4$ mg; $B_{1}, 1,5$ mg; $B_{2}, 6$ mg; $B_{12}, 18$ mcg; E, 18 UI; niacina, 36 mg; ácido pantotênico, 12 mg; ácido fólico, 0,75 mg; biotina, 120 mcg e antioxidante, $37,5 \mathrm{mg}$.

2. Enriquecimento por kg de ração: cobre, 10 mg; ferro, 80 mg; zinco, 50 mg; manganês, 85 mg; selênio, 0,15 mg.

* A porção variável foi constituída de caulim e ou cloreto de potássio e ou cloreto de amônia para se atingir os níveis de $0,0 \%$ e $1,2 \%$ de $\mathrm{KCl}$ e $0,0 \%, 0,2$ e $0,4 \%$ de $\mathrm{NH}_{4} \mathrm{Cl}$.

Ciênc. agrotec., Lavras, v. 29, n. 1, p. 185-192, jan./fev. 2005 


\section{RESULTADOS E DISCUSSÃO}

Os dados meteorológicos e os valores do ITGU observados encontram-se na Tabela 2.

Estes resultados estão acima dos apresentados por Lopes (1986), que comparando instalações para criação de frangos de corte, do ponto de vista higrotérmico, nas condições climáticas brasileiras, encontrou valores de ITGU variando de 63 a 70,8, como sendo a zona de conforto térmico para frangos de corte, dos 28 a 49 dias de idade. Todavia, corrobora com Tinôco (1988), que estudando o sistema de resfriamento adiabático evaporativo na produção de frangos de forte, verificou que valores de ITGU superiores a 75 causam desconforto em frangos de corte acima de 15 dias de idade.

\section{Respostas fisiológicas}

As médias dos parâmetros estudados encontram-se na Tabela 3. Para a temperatura retal e freqüência respiratória não se verificou efeito significativo $(P>0,05)$ dos fatores estudados. Os resultados obtidos para TR, são semelhantes aos reportados por Deyhim e Teeter (1991), Smith (1994) e Borges et al. (1999), que não observaram efeito da adição de $\mathrm{KCl}$, sobre a TR de frangos de corte estressados por calor. Para o nível energético os resultados assemelham-se aos obtidos por Campos (1999). O KCl afetou significativamente $(\mathrm{P}<0,05)$ a TS no turno da manhã em relação ao controle $\left(34,76^{\circ} \mathrm{C}\right.$ vs $\left.35,15^{\circ} \mathrm{C}\right)$.

TABELA 2 - Valores médios da temperatura do bulbo seco (BS), bulbo úmido (BU), termômetro de globo negro (TGN), umidade relativa do ar (UR), valores absolutos da temperatura máxima e mínima, temperatura do ponto de orvalho (Tpo) e índice de temperatura do globo negro e umidade (ITGU) nos turnos da manhã e da tarde, e média diária.

\begin{tabular}{|c|c|c|c|c|c|c|c|c|}
\hline \multirow{2}{*}{ Turnos } & \multicolumn{6}{|c|}{ Temperatura do ar $\left({ }^{\circ} \mathrm{C}\right)$} & \multirow{2}{*}{ UR \%) } & \multirow{2}{*}{ ITGU } \\
\hline & BS & BU & TGN & MÁX & MÍN & Тро & & \\
\hline Manhã & 26,3 & 23,3 & 26,5 & - & - & 22,5 & 78 & 76 \\
\hline Tarde & 32,3 & 26,2 & 32,6 & - & - & 24,7 & 63 & 83 \\
\hline Média diária & 29,3 & 24,7 & 29,6 & 32,7 & 22,85 & 23,0 & 70 & 79 \\
\hline
\end{tabular}

TABELA 3 - Efeito da suplementação de $\mathrm{KCl}, \mathrm{NH}_{4} \mathrm{Cl}$ e o nível energético da ração sobre as temperaturas superficial (TS) e retal (TR), frequiência respiratória (FR), ingestão de água (IA), pH sangüíneo (pH), ganho de peso (GP) e conversão alimentar (CA) de frangos de corte no verão.

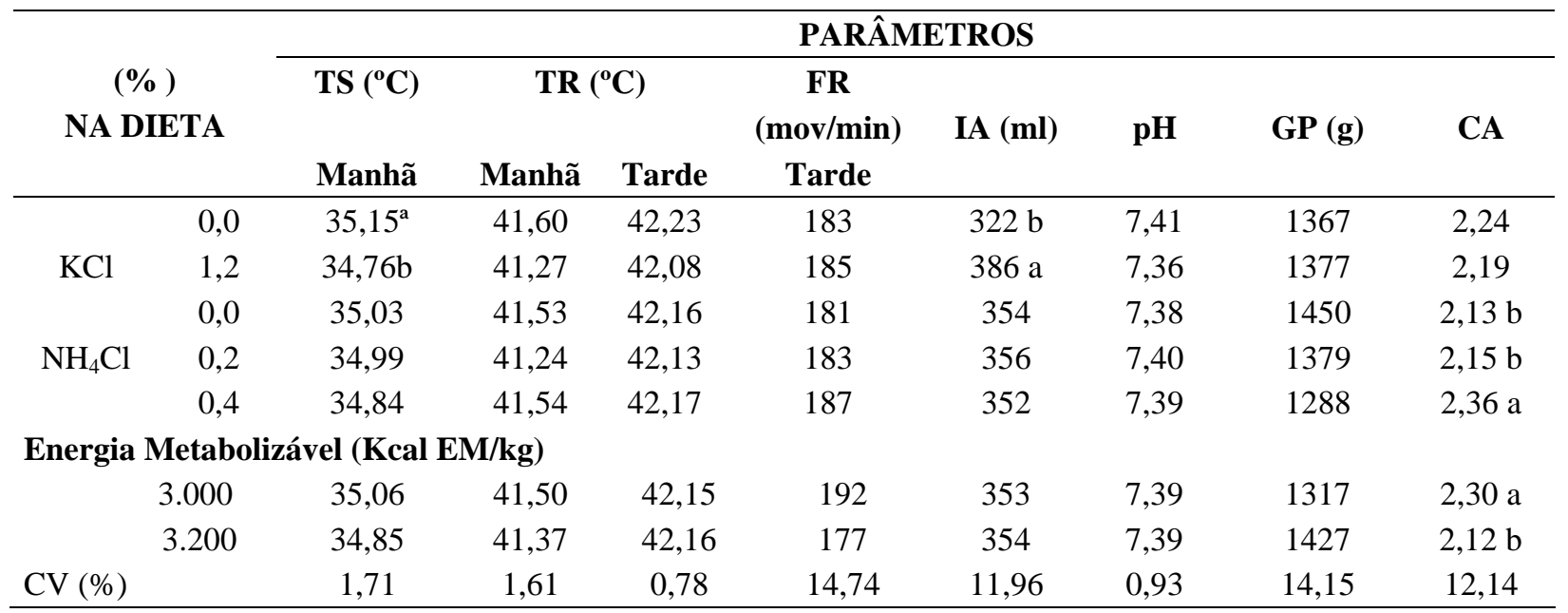

Médias seguidas de letras diferentes na coluna, dentro de cada fator, diferem entre si pelo teste de Tukey $(\mathbf{P}<\mathbf{0 , 0 5 )}$.

Ciênc. agrotec., Lavras, v. 29, n. 1, p. 185-192, jan./fev. 2005 
A média da freqüência respiratória de todos os tratamentos encontra-se dentro dos limites de 177 a 192 mov/min, valores que representam aumento de 664\% em relação à média considerada normal $(25 \mathrm{mov} / \mathrm{min})$ para frangos de corte em condições termoneutras, indicando que os animais acionaram este mecanismo de dissipação de calor, ante a condição ambiental estressante revelada pelo índice de conforto térmico (ITGU = 83) no turno da tarde. Estes resultados são semelhantes aos de Linsley e Burger (1964) e Bottje et al. (1985), que observaram aumentos de até dez vezes o valor normal da FR, em aves submetidas a estresse calórico.

Não se verificou efeito $(\mathrm{P}>0,05)$ do $\mathrm{KCl}$ ou $\mathrm{NH}_{4} \mathrm{Cl}$ sobre o $\mathrm{pH}$ (Tabela 3). Resultados semelhantes aos observados por Teeter e Smith (1986), que ao suplementarem com níveis de 0,05 e $0,15 \%$ de $\mathrm{KCl}$ e Teeter et al. (1985) com níveis de 0,3 e $1 \%$ de $\mathrm{NH}_{4} \mathrm{Cl}$, não verificaram efeito sobre o $\mathrm{pH}$. Todavia, esses valores são contrários aos registrados por Deyhim e Teeter (1991), que observaram redução significativa do $\mathrm{pH}$ quando suplementaram com $0,5 \%$ de $\mathrm{KCl}$, bem como os registrados por Teeter et al. (1986) e Branton et al. (1986), que ao suplementarem com 0,3 a $0,63 \%$ de $\mathrm{NH}_{4} \mathrm{Cl}$, observaram também redução significativa do pH sanguíneo de frangos de corte.

A ingestão de água (IA) foi influenciada $(\mathrm{P}<0,01)$ apenas pelo $\mathrm{KCl}$, tendo a suplementação de $1,2 \% \mathrm{KCl}$ elevado $(\mathrm{P}<0,05)$ a IA de 322 para 386 (ml/ave/dia) em relação aos não suplementados. Resultados similares foram observadas por Smith e Teeter (1987), Deyhim e Teeter (1991), Belay e Teeter (1993) e Smith (1994), corrobora também com Souza et al. (1999), que registrou efeito linear positivo da adição de $\mathrm{KCl}$ (nos níveis de 0 a 2\%) sobre a ingestão de água em frangos de corte criados no verão.

\section{Parâmetros de desempenho}

Os resultados obtidos para o ganho de peso assemelham-se aos de Borges et al. (1999), que, submetendo frangos de corte a estresse calórico de $25^{\circ}$ a $35^{\circ} \mathrm{C}$ e $63,5 \%$ de umidade relativa, suplementando a ração com KCl nos níveis de 0,5 e 1,0\%, não detectaram efeito significativo sobre este parâmetro. Resultados semelhantes também foram encontrados por Smith (1994) expondo frangos de corte a estresse calórico e suplementando a água de bebida com $0,48 \% \mathrm{KCl}$ e Silva e Flemming (1990), Smith e Teeter (1993) e Junqueira et al. (1999) suplementando com $\mathrm{NH}_{4} \mathrm{Cl}$ e Campos (1995), Leeson et al. (1996) e Cheng et al. (1997) que, empre- gando rações com níveis diferentes de energia, não detectaram efeito significativo sobre o GP em frangos de corte sob condições de estresse térmico.

Porém, estes resultados são contrários aos observados por Teeter e Smith (1986) e Smith e Teeter (1987, 1989, 1992, 1993), que constataram efeitos positivos da suplementação de $\mathrm{KCl}$ sobre o GP de frangos de corte sob estresse calórico, e com os registrados por Teeter et al. (1985) e Teeter e Smith (1986), que revelaram maior GP com a suplementação de $\mathrm{NH}_{4} \mathrm{Cl}$. Com relação ao nível de energia da ração, diferiram dos registrados por Bertechini et al. (1991) e Oliveira Neto et al. (1999), que detectaram efeito linear positivo do nível energético da ração sobre o GP de frangos de corte.

O nível $0,4 \% \mathrm{NH}_{4} \mathrm{Cl}$ apresentou pior CA $(\mathrm{P}<0,05)$ em relação ao controle e ao nível de $0,2 \%$ $\mathrm{NH}_{4} \mathrm{Cl}$ (2,36 vs 2,13 e 2,15, respectivamente), e o alto nível energético melhorou significativamente $(\mathrm{P}<0,05)$ este parâmetro em relação ao nível baixo (2,12 vs 2,30, respectivamente). Estes resultados são semelhantes aos obtidos por outros autores (BERTECHINI et al., 1991; OLIVEIRA NETO et al., 1999), que fornecendo rações com níveis crescentes de energia metabolizável, observaram efeito linear positivo $(\mathrm{P}<0,05)$ na $\mathrm{CA}$ e com Silva e Flemming (1990), Teeter e Smith (1986) e Smith e Teeter (1992), que não detectaram melhoria na CA com a suplementação de $\mathrm{NH}_{4} \mathrm{Cl}$. Estes achados são semelhantes aos de Borges et al. (1999), que não observaram efeito da suplementação de $\mathrm{KCl}$ nos níveis de 0,4 a 2,0\%, sobre este parâmetro. Todavia, discordam dos resultados obtidos por Smith e Teeter (1987, 1989, 1992, 1993), que verificaram efeitos da suplementação de KCl sobre a CA de frangos de corte sob estresse calórico. A elevação do nível energético da ração, com a utilização de óleos e gorduras, reduz o incremento calórico das dietas, sendo favorável às aves criadas durante o verão, porque recupera o consumo de energia, melhorando assim a conversão alimentar (CAMPOS, 1999).

A piora observada na CA com a suplementação de $0,4 \%$ de $\mathrm{NH}_{4} \mathrm{Cl}$, possivelmente ocorreu devido à ação tóxica do $\mathrm{NH}_{4} \mathrm{Cl}$. Teeter e Smith (1986), ao estudarem os efeitos da suplementação de cloreto de amônia na água de bebida de frangos de corte estressado pelo calor, observaram que $0,2 \%$ de $\mathrm{NH}_{4} \mathrm{Cl}$ reduziu o $\mathrm{pH}$ do sangue, melhorou o ganho e a CA. Mas concluíram que o $\mathrm{NH}_{4} \mathrm{Cl}$ embora seja efetivo no combate aos efeitos do estresse calórico, níveis em torno de $0,5 \%$ de $\mathrm{NH}_{4} \mathrm{Cl}$ já apresentam toxidez..

Para a temperatura superficial (TS) houve interação entre $\mathrm{KCl}$ e $\mathrm{NH}_{4} \mathrm{Cl}$, no turno da tarde (Tabela 4). 
Verificou-se que na ausência do $\mathrm{KCl}$ a suplementação de $\mathrm{NH}_{4} \mathrm{Cl}$ não afetou a TS $(\mathrm{P}>0,05)$ em relação aos não suplementados, todavia, o nível de $0,2 \% \mathrm{NH}_{4} \mathrm{Cl}$ apresentou média inferior ao nível de $0,4 \% \mathrm{NH}_{4} \mathrm{Cl}(\mathrm{P}<0,05)$. $\mathrm{Na}$ presença do $\mathrm{KCl}$, o nível de $0,2 \% \mathrm{NH}_{4} \mathrm{Cl}$ elevou a TS em relação ao controle $(\mathrm{P}<0,05)$.

Para o CR, verificou-se interação $(\mathrm{P}<0,05)$ do $\mathrm{KCl}$ com o nível de energia da dieta (Tabela 5). A suplementação de $\mathrm{KCl}$, só apresentou efeito $(\mathrm{P}<0,05)$ sobre o CR quando adicionada à ração com o nível energético alto (3200 Kcal de EM/kg), havendo redução no CR na presença do $\mathrm{KCl}$ em relação à ausência (2.887 g vs 3093 g, respectivamente). As divergências observadas na literatura, correlacionadas ao efeito do $\mathrm{KCl}$ sobre o consumo de ração, podem ser explicadas em função dos diferentes níveis energéticos das rações utilizadas em cada pesquisa. Observa-se que no nível energético (3000 Kcal EM/kg) não houve diferença significativa no CR, resultados que estão de acordo com os encontrados por Smith e Teeter (1992) e Borges et al. (1999), que expondo frangos de corte a estresse calórico e suplementando a dieta com $\mathrm{KCl}$, não observaram efeito significativo sobre este parâmetro, bem como os resultados obtidos por Souza et al. (2002a,b) que não observaram efeito $(\mathrm{P}>0,05)$ com a suplementação de $\mathrm{KCl}$ nos níveis de 0,4 a 2,0\%, sobre CR.

Em relação ao fator energia, os resultados obtidos discordam dos encontrados por Bertechini et al. (1991) e Leeson et al. (1996), que verificaram redução significativa no consumo de ração de frango de corte com a elevação do nível de energia da ração.

TABELA 4 - Médias da temperatura superficial (TS) de frangos de corte no verão, no turno da tarde, em função dos níveis de $\mathrm{NH}_{4} \mathrm{Cl}$ e $\mathrm{KCl}$ adicionados à ração.

\begin{tabular}{|c|c|c|c|}
\hline \multirow[b]{2}{*}{ \% KCI NA DIETA } & \multicolumn{3}{|c|}{$\% \mathrm{NH}_{4} \mathrm{Cl}$ NA DIETA } \\
\hline & 0,0 & 0,2 & 0,4 \\
\hline 0,0 & $35,25 \mathrm{ab}$ & $34,74 b$ & 35,56 a \\
\hline 1,2 & $34,90 \mathrm{~b}$ & 35,85 a & $35,06 \mathrm{ab}$ \\
\hline CV (\%) & & 1,61 & \\
\hline
\end{tabular}

Médias seguidas de letras diferentes, na linha diferem entre si pelo teste de Tukey $(P<0,05)$.

TABELA 5 - Médias do consumo de ração (CR) de frangos de corte no verão, em função da suplementação de $\mathrm{KCl}$ e o nível energético da ração.

\begin{tabular}{ccc}
\hline & \multicolumn{2}{c}{ KCl (\%) } \\
\cline { 2 - 3 } EM (Kcal EM/kg) & 0,0 & 1,2 \\
\hline 3000 & 2929 & 3029 \\
3200 & $3093 \mathrm{a}$ & $2887 \mathrm{~b}$ \\
CV (\%) & & 8,56 \\
\hline
\end{tabular}

Médias seguidas de letras diferentes, na linha diferem pelo teste de $\mathrm{F}(\mathrm{P}<0,05)$. 


\section{CONCLUSÕES}

Nas condições deste experimento concluiu-se que:

A temperatura retal, a freqüência respiratória e o pH sangüíneo não foram afetados pelo nível energético da ração nem pelos cloretos de potássio e de amônia.

O nível energético da ração e o cloreto de potássio influenciam a temperatura superficial de frangos de corte sob condições de estresse calórico, provavelmente pela maior ingestão de água provocada pelo $\mathrm{KCl}$ e pelo menor incremento calórico dos lipídeos adicionados á ração.

A adição de $0,4 \%$ de cloreto de amônia à ração piora a conversão alimentar de frangos de corte na fase final.

\section{REFERÊNCIAS BIBLIOGRÁFICAS}

BELAY, T.; TEETER, R. G. Broiler water balance ande thermobalance during termoneutral and high ambient temperature exposure. Poultry Science, Champaign, v. 72, n. 1, p. 116-124, Jan. 1993.

BERTECHINI, A. G.; ROSTAGNO, H. S.; SILVA, M. A. Efeito da temperatura ambiente e nível de energia da ração sobre o desempenho e a carcaça de frangos de corte. Revista da Sociedade Brasileira de Zootecnia, Viçosa, v. 20, n. 3, p. 218-228, maio/jun. 1991.

BORGES, S. A. et al. Suplementação de cloreto de potássio para frangos de corte submetido a estresse calórico. Revista Brasileira de Zootecnia, Viçosa, v. 28, n. 2, p. 313-319, mar./abr. 1999.

BOTTJE, W. G.; HARRISON, P. C. The effect os tap water, sodium bicarbonate and calcium chlorid onblood acid-base balance cockerels subjected to heat stress. Poultry Science, Champaing, v. 64, n. 1, p. 107-113, 1985.

BRANTON, S. L.; REECE, F. N.; DEATON, J. W. Use of ammonium chloride and sodium bicarbonate in acute heat exporure of broilers. Poultry Science, Champaign, v. 65, n. 9, p. 1659-1663, Sept. 1986.

CAMPOS, S. S. Efeito do nível de energia da dieta, idade e temperatura ambiente sobre a temperatura superficial, carga térmica radiante e temperatura retal de frangos de corte. 1995. 102 f. Dissertação (Mestrado em Zootecnia) - Universidade Estadual Paulista, Jaboticabal, 1995.
CAMPOS, S. S. Efeitos da energia dietética, densidade populacional, altura de cama e época do ano sobre parâmetros termorreguladores, zootécnicos e da cama de frangos de corte. 1999. $62 \mathrm{f}$. Tese (Doutorado em Zootecnia) - Universidade Estadual Paulista, Jaboticabal, 1999.

CERNIGLIA, G. J.; HERBERT, J. A.; WATTS, A. B. The effect of constant temperature and ration on the performace of sexed broilers. Poultry Science, Champaign, v. 62, n. 5, p. 746-754, May 1983.

CHENG, T. K.; HAMRE, M. L.; COON, C. N. Effect of environmental temperature, dietary protein, and energy levels on broiler performance. Journal of Applied Poultry Research, Athens, v. 6, p. 1-17, 1997.

COOPER, M. A.; WASHBURN, K. W. The relationships of body temperature to weigth gain, feed consumption, and feed utilization in broilers under heat stress. Poultry Science, Champaign, v. 77, n. 2, p. 237-242, 1998.

DEYHIM, F.; TEETER, R. G. Research note: sodium and potassium chloride drinking water supplementation effects on acid-base balance and plasma corticosterone in broilers reared in thermoneutral and heat-distressed environments. Poultry Science, Champaign, v. 70, n. 12, p. 2551-2553, Dec. 1991.

JUNQUEIRA, O. M. et al. Desempenho e parâmetros hematológicos de frangos de corte submetidos à restrinção alimentar recebendo soluções hidroeletrolíticas. Revista Brasileira de Ciência Avícola, São Paulo, v. 1, n. 1, p. 55-59, 1999.

LEESON, S.; CATON, L.; SUMMERS, J. D. Broiler response to diet energy. Poultry Science, Champaign, v. 75, n. 4, p. 529-535, Apr. 1996.

LINSLEY, J. G.; BURGER, R. E. Respiratory and cardiovascular responses in the hyperthermic domestic cock. Poultry Science, Champaign, v. 43, n. 2, p. 291305, 1964.

LOPES, S. P. Estudo de galpões para a criação de frangos de corte, do ponto de vista higrotérmico, nas condições climáticas brasileiras. 1986. 155 f. Dissertação (Mestrado em Engenharia Civil) - Universidade Federal do Rio Grande do Sul, Porto Alegre, 1986. 
OLIVEIRA NETO, A. R. de et al. Níveis de energia metabolizável para frangos de corte no período de 22 a 42 dias de idade mantidos em condições de estresse de calor. Revista Brasileira de Zootecnia, Viçosa, v. 28, n. 5, p. 1054-1062, jul./ago. 1999.

RICHARDS, S. A. The significance of changes in the temperature of the skin and body core of the chicken in the regulation of heat loss. The Journal Physiology, Cambridge, v. 216, p. 1-10, 1971.

ROSTAGNO, H. S. et al. Composição de alimentos e exigências nutricionais de aves e suínos: tabelas brasileiras. Viçosa: UFV, 1994. 61 p.

SAKOMURA, N. K. et al. Efeito da temperatura sobre o consumo de ração e de energia metabolizável para poedeiras comerciais. Revista da Sociedade Brasileira de Zootecnia, Viçosa, v. 22, n. 5, p. 715-722, 1993.

SAS INSTITUTE. Institute user's guide: statistical analysis system institute. 5. ed. North Carolina, 1996. 956 p.

SILVA, A. V. F.; FLEMMING, J. S. Interferência da temperatura no equilibrio ácido-base em frangos de corte e sua resposta frente à suplementação com bicarbonato de sódio, cloreto de amônia e stacidem. Revista Setor de Ciências Agrárias, Curitiba, v. 11, n. 1/2, p. 23-30, 1990.

SMITH, M. O. Effects of eletrolyte and lighting regimen on growth of heat-distressed broilers. Poultry Science, Champaign, v. 73, n. 2, p. 350-353, Feb. 1994.

SMITH, M. O.; TEETER, R. G. Potassium balance of the 5 to 8-wek-old broiler exposed to constante heat or cycling high temmperatur stress and the effects of supplemental potassium chloride on body weight gain and feed efficiency. Poultry Science, Champaign, v. 66, n. 3, p. 487-492, Mar. 1987.

SMITH, M. O.; TEETER, R. G. Effects of sodium and potassium salts on gain, water consumption and body temperature of 4 to 7 week-old reat stressed broilers. Nutrition Reports International, Stoneham, v. 40, p. 161-169, 1989.
SMITH, M. O.; TEETER, R. G. Effects of potassium chloride supplementation on growth of heat-distressed broilers. Journal of Applied poultry Research, Athens, v. 1, p. 321-324, 1992.

SMITH, M. O.; TEETER, R. G. Carbon dioxide ammonium chloride, potassium chloride, and performance of heat distressed broilers. Journal of Applied Poultry Research, Athens, v. 2, p. 61-66, 1993.

SOUZA, B. B. et al. Efeito da adição de cloreto de potássio à dieta sobre o comportamento fisiológico e produtivo de frangos de corte no verão. In: CONFERÊNCIA APINCO DE CIÊNCIA E TECNOLOGIA AVÍCOLAS, 1999, Campinas. Anais... Campinas: FACTA, 1999. p. 28.

SOUZA, B. B. et al. Efeito da suplementação de cloreto de potássio na dieta sobre o equilíbrio ácido-básico e o desempenho de frangos de corte no verão. Ciência e Agrotecnologia, Lavras, v. 26, n. 6, p. 1297-1304, nov./dez. 2002a.

SOUZA, B. B. et al. Efeitos dos cloretos de Potássio e de amônia sobre o desempenho e deposição de gordura na carcaça de frangos de corte criados no verão. Revista Brasileira de Ciência Avícola, Campinas, v. 4, n. 3, p. 209-218, set./dez. 2002b.

TEETER, R. G. et al. Chronic stress and respiratory alkalosis: occurrence and treatment in broiler chicks. Poultry Science, Champaign, v. 64, n. 6, p. 1060-1064, June 1985.

TEETER, R. G.; SMITH, M. High chronic ambient temperature stress effects on broiler acid-base balance and their response to supplemantal ammonium chloride potassium chloride, and potassium carbonate. Poultry Science, Champaign, v. 65, n. 9, p. 1777-1781, Sept. 1986.

TINÔCO, I. F. F. Resfriamento adiabático (Evaporativo) na produção de frangos de corte. $1988.92 \mathrm{f}$. Dissertação (Mestrado em Engenharia Agrícola) - Universidade Federal de Viçosa, Viçosa, 1988. 